\title{
The association between residual neuromuscular blockade (RNMB) and critical respiratory events: a prospective cohort study
}

Faraj K Alenezi ${ }^{1,2^{*}}$ (D) Khalid Alnababtah ${ }^{3}$, Mohammed M Alqahtani ${ }^{4}$, Lafi Olayan ${ }^{1}$ and Mohammed Alharbi ${ }^{1,2}$

\begin{abstract}
Background: Inadequate neuromuscular recovery might impair pulmonary function among adult patients who undergo general anaesthesia and might thus contribute to critical respiratory events in the post-anaesthesia care unit (PACU). The pilot study aims to understand the baseline incidence of residual neuromuscular blockade (RNMB) and postoperative critical respiratory events (CREs), which are described in a modified Murphy's criteria in the PACU.

Method: This is a prospective cohort study from January to March 2017 from a tertiary hospital in Saudi Arabia with thirty adult patients over 18 years old scheduled for elective surgery under general anaesthesia with neuromuscular blocking drugs (NMBDs) who were enrolled in the study. The Mann-Whitney $U$ tests, chi-square tests and independent-samples $T$ tests were used. The train-of-four (TOF) ratios were measured upon arrival in the PACU by using acceleromyography with TOF-Scan. Subjects' demographics, perioperative data and the occurrence of postoperative CREs in the PACU were recorded.

Results: Twenty-six (86.7\%) patients out of thirty in the study have received rocuronium as NMBDs whilst neostigmine as a reversal drug with only $23(76.7 \%)$. The incidence of RNMB (TOF ratio <0.9) was in 16 patients (53.3\%). The incidence of RNMB was significantly higher in female patients $(p=0.033)$, in patients who had not undergone quantitative neuromuscular monitoring before extubation $(p=0.046)$ and in patients with a shorter duration of surgery $(p=0.001)$. Postoperative CREs occurred in twenty patients $(66.7 \%)$, and there were significantly more of these CREs among patients with RNMB ( $p=0.001)$. In addition, a statistically significant difference was observed in the occurrence of CREs according to body mass index ( $p=0.047$ ).

Conclusion: This research showed that RNMB is a significant contributing factor to the development of critical respiratory events during PACU stay. Therefore, routine quantitative neuromuscular monitoring is recommended to reduce the incidence of RNMB.
\end{abstract}

Keywords: Neuromuscular blocking drugs, Residual neuromuscular blockade, Critical respiratory events

\footnotetext{
* Correspondence: farajalenezi@gmail.com

${ }^{1}$ Anesthesia Technology Program, College of Applied Medical Sciences, King

Saud bin Abdul-Aziz University for Health Sciences, Riyadh, Saudi Arabia

${ }^{2}$ King Abdullah International Medical Research Center, Riyadh, Saudi Arabia

Full list of author information is available at the end of the article
}

\section{$\triangle B M C$}

(c) The Author(s). 2021 Open Access This article is licensed under a Creative Commons Attribution 4.0 International License, which permits use, sharing, adaptation, distribution and reproduction in any medium or format, as long as you give appropriate credit to the original author(s) and the source, provide a link to the Creative Commons licence, and indicate if changes were made. The images or other third party material in this article are included in the article's Creative Commons licence, unless indicated otherwise in a credit line to the material. If material is not included in the article's Creative Commons licence and your intended use is not permitted by statutory regulation or exceeds the permitted use, you will need to obtain permission directly from the copyright holder. To view a copy of this licence, visit http://creativecommons.org/licenses/by/4.0/ The Creative Commons Public Domain Dedication waiver (http://creativecommons.org/publicdomain/zero/1.0/) applies to the data made available in this article, unless otherwise stated in a credit line to the data. 


\section{Introduction}

Many patients are at high risk of adverse events during the early postoperative period, which might be caused by anaesthetic or surgical procedures. These adverse events include cardiovascular or respiratory complications (Buhre and Rossaint 2003). Therefore, areas known as post-anaesthesia care units (PACU) have been established in many hospitals worldwide, which are intended to provide specialised care and minimise morbidity and mortality through the timely detection or prevention of adverse events (Kiekkas et al. 2014). In clinical practice, neuromuscular blocking drugs (NMBDs) are commonly used by anaesthesiologists during general anaesthesia in order to maintain optimal surgical conditions by maintaining deep muscle relaxation and to facilitate tracheal intubation (Claudius et al. 2009). However, their effects might continue after extubation: this is called residual neuromuscular blockade (RNMB). According to Murphy et al. (2008a), between 33 and $64 \%$ of patients have evidence of incomplete neuromuscular recovery or RNMB during their stay in the PACU, despite the use of techniques proven to limit the degree of RNMB, such as reversal drugs. The incidence of RNMB ranges between 26 and $88 \%$, based on the type of NMBDs, reversal drugs or neuromuscular monitoring used (Cammu et al. 2012; Fortier et al. 2015). The RNMB can be reliably detected through the use of neuromuscular monitoring such as train-of-four (TOF) monitoring, which is according to Murphy et al. (2011) is considered one of the most commonly used approaches in clinical practice. This method, however, is used during recovery from the application of NMBDs to objectively decide how well the patient's muscles are able to function, which includes the application of electrical stimulation to nerves and the recording of muscle responses, called the TOF ratio (Butterworth 2013). The TOF ratio when it is $\geq 0.90$ is considered the gold standard for defining adequate neuromuscular recovery, whereas RNMB is present when the TOF ratio $<0.90$ (Murphy 2006). Accordingly, The RNMB might place patients at an increased risk of critical respiratory events (CREs) in the PACU. Evidence from observational studies suggests that TOF ratios when it is less than 0.90 are usually associated with the incidence of CREs that include inadequate recovery of pulmonary function, upper airway obstruction, impaired pharyngeal reflexes, decreased muscle coordination, impaired hypoxic ventilatory response and increased risk of aspiration (Cammu et al. 2012; Herbstreit et al. 2009; Murphy et al. 2008a).

To date, the incidence of RNMB and its association with CREs during the PACU stay has not been investigated in Saudi Arabia. In addition, the issue of whether or not neuromuscular monitoring is usually used has not been investigated. Therefore, this pilot study is aiming to understand the baseline incidence of residual neuromuscular blockade (RNMB) and postoperative critical respiratory events (CREs), which are described in a modified Murphy's criteria, the feasibility of measuring TOF in the PACU stay in a tertiary hospital in Saudi Arabia.

\section{Methods}

\section{Study design}

A pilot prospective cohort design was used in this study which is part of a student project at Cardiff University. The study was conducted in the post-anaesthesia care unit (PACU) at the National Guard Hospital, King Abdulaziz Medical City in Riyadh, Saudi Arabia. The study has been approved by the King Abdullah International Medical Research Centre (KAIMRC) at King Abdulaziz Medical City (IRBC/1235/16). Informed written consent was obtained from all patients before entry into the study. Participants were enrolled between 21st January 2017 and 21st March 2017. All participants were screened for their eligibility based on the inclusion and exclusion criteria (Table 1).

The following baseline demographic variables were collected: age, gender, height, weight and body mass index (BMI). Operative variables collected included the type and duration of the operation. The anaesthesiologists were blinded to the patients' participation in the study, and the NMBDs were supervised according to the standards of patient care in PACU and whether these patients required oxygen following their extubation in the operating theatre.

On arrival at the PACU, the type and dose of neuromuscular blockade drugs (NMBDs) and reversal drugs and the duration of surgery are recorded by qualified nurses in PACU. They also measured the following postoperative outcomes: peripheral oxygen saturation $\left(\mathrm{SpO}_{2}\right)$, respiratory rate $(\mathrm{RR})$ and TOF ratio during the first $30 \mathrm{~min}$ of arrival into the PACU in which all of them were obtained by the researcher. The research assistant obtained TOF ratio via acceleromyography (quantitative neuromuscular monitoring) at the adductor pollicis of the thumb (TOF-Scan ${ }^{\mathrm{Tu}}$, IdMed, Marseille, France). When the patients experienced any of CREs based on the modified Murphy's criteria within the first 30 min in admission to the PACU, the nurses have directly informed the researcher about these changes in the patients' condition as shown in Table 2.

\section{Statistical analysis}

All statistical analysis for the current study was performed by using the SPSS (version 23.0). Categorical data were presented as percentages or frequencies, and the chi-square test was used for comparison. For nonnormally distributed data, the Mann-Whitney $U$ test, median and interquartile range (IQR) were used, whilst 
Table 1 Inclusion and exclusion criteria

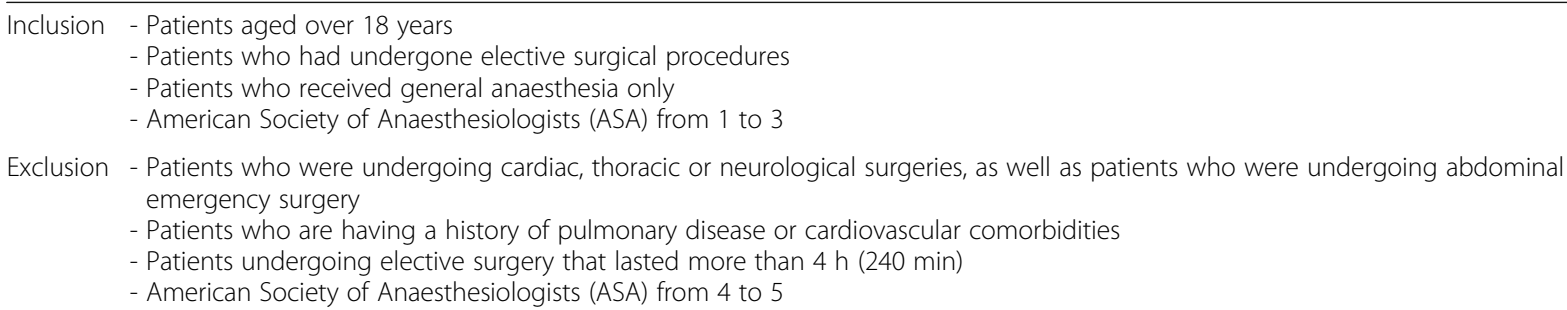

the mean, standard deviation (SD) and independentsamples $T$ tests were used if normally distributed. A $p$ value of less than 0.05 was considered for the statistically significant level.

\section{Results}

A total of 120 patients were screened for their eligibility based on the inclusion and exclusion criteria at a preanaesthesia clinic over a period of 4 weeks (Table 1 ). Nineteen patients with chronic obstructive pulmonary disease (COPD), 22 with abdominal emergency surgery and 49 who undergone elective surgery that lasted more than $4 \mathrm{~h}$ (240 $\mathrm{min})$ were excluded. A total of 30 patients, consisting of 17 males and 13 females, were recruited for analysis (Fig. 1).

Demographic data of the population, surgical and anaesthesia details are summarised in Table 3. The median age of participants was 35 years. The majority of these participants were male $(56.7 \%)$, whilst female patients represented $43.3 \%$ of the sample. Based on Fortier et al. (2015) and Murphy et al. (2015), patients' age was categorized into two age groups: younger patients (age 18 to 50 years) and elderly patients (age $\geq 51$ years). More than half of the studied patients had American Society

Table 2 Types of critical respiratory events (modified Murphy's criteria)

1. Upper airway obstruction: if the patient required an intervention such as:

o Oral airway

o Jaw thrust

o Nasal airway

2. Mild-moderate hypoxaemia $\left(\mathrm{SpO}_{2}\right.$ of $\left.93-90 \%\right)$

3. Severe hypoxaemia $\left(\mathrm{SpO}_{2}<90 \%\right)$

4. Signs of respiratory distress or impending ventilation failure:

o Accessory muscle use

o Tracheal tug

o Respiratory rate $>20$ breaths per minute

5. Patient could not breathe deeply whilst asked for by the PACU

nursing staff

6. Patient complaining of upper airway muscle weakness or symptoms

of respiratory:

o Difficulty swallowing: ask the patient to swallow a sip of water

o Difficulty speaking

o Difficulty breathing

7. Patient requiring re-intubation in the PACU

8. Clinical evidence or suspicion of pulmonary aspiration after tracheal extubation (gastric contents observed in the oropharynx and hypoxaemia) of Anaesthesiologists Physical Status (ASA-PS) class II (56.7\%), followed by ASA-PS class I (33.3\%). The majority of the cohort was undergoing general surgeries (43.3\%) and ENT surgeries (33.3\%), followed by urology surgeries (13.3\%). The most frequently used NMBD during the current study was rocuronium with an initial dose of $50 \mathrm{mg}(86.7 \%)$, whilst the most frequently used reversal drug was neostigmine $(76.7 \%)$. The mean BMI among the participants was $29.45 \pm 5.56 \mathrm{~kg} / \mathrm{m}^{2}$.

The incidence of RNMB (TOF ratio < 0.90 ) was $53.3 \%$ (16/30). In comparing the preoperative variables among patients who had RNMB on PACU admission, the chisquare test clearly showed that there were no significant differences between the incidence of RNMB according to the age of patients ( $18-50$ vs. $\geq 51$ years) or ASA-PS class, with $p=0.0544$ and $p=0.103$, respectively. The same test demonstrated that the incidence of the RNMB was significantly higher in the female gender $(76.9 \%$ vs. $35.3 \%, p=0.033$ ) (Fig. 2), in patients who had not had neuromuscular monitoring before extubation $(66.7 \%$ vs. $22.2 \%, p=0.046)$, and in shorter duration of surgery (81.8\% vs. $21.4 \%, p=0.001)$. The independent-samples $T$ tests demonstrated no significant differences in RNMB in relation to BMI $(p=0.294)$. In comparing patients who had RNMB upon arrival in the PACU with those who did not, the Mann-Whitney $U$ test demonstrated a significant relationship between the incidence of RNMB and both oxygen desaturation and respiratory rate, at $p$ $=0.034$ and $p=0.025$, respectively (Table 4).

Overall, $66.7 \%$ of patients who underwent elective surgeries under general anaesthesia experienced postoperative CREs, compared with $33.3 \%$ who did not (Table 5). The Mann-Whitney $U$ test revealed that there was no significant difference in postoperative CREs in the PACU between age groups and groups with long vs. short surgery times. The median of the TOF ratio upon arrival in the PACU was 0.88 in patients with postoperative CREs. The chi-square test demonstrated that RNMB (TOF ratio $<0.90)$ was more frequent among those participants with postoperative CREs ( $75 \%$ vs. $10 \%, p=0.001)$. The Mann-Whitney $U$ test demonstrated no significant association between the patients' temperature and the incidence of CREs. The independent-samples $T$ tests showed a significant difference in postoperative CREs 


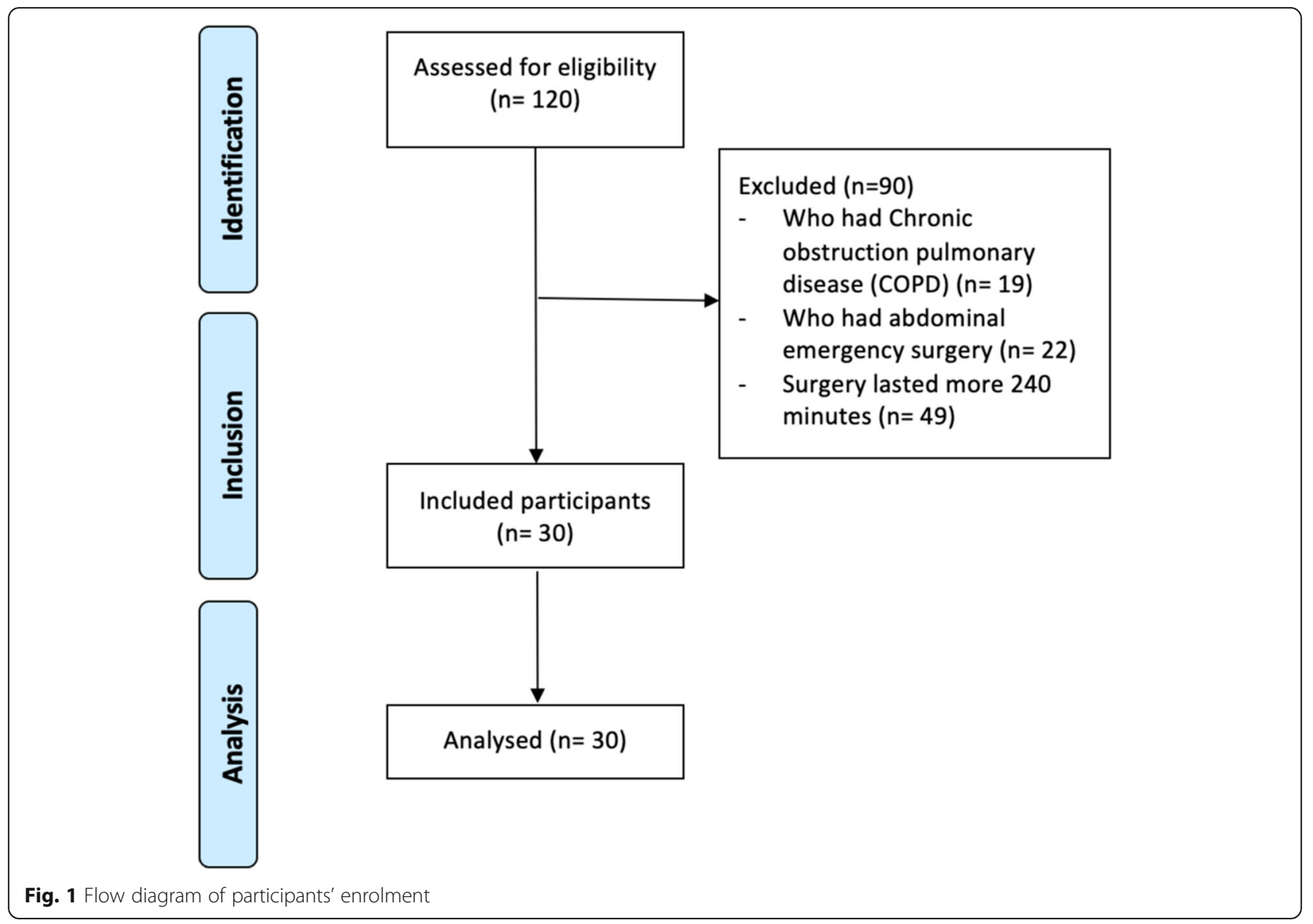

between the two BMI groups $(31.23 \pm 6.1$ vs. $26.78 \pm$ 3.94, $p=0.047)$.

During the present study, the incidence of critical respiratory events in the PACU was defined according to the described criteria by Murphy et al. (2008a). Based on these criteria, twenty patients experienced postoperative CREs during the first $30 \mathrm{~min}$ in the PACU in this current study. The one or two signs of CREs commonly observed in the sample of this study with respiratory distress (50\%), mild to moderate hypoxaemia (30\%) and upper airway obstruction (16.7\%). The other CREs recorded were severe hypoxaemia (13.3), upper airway weakness $(10 \%)$ and inability to breathe deeply (6.7\%) as in Table 6. None of the patients had pulmonary respiratory disease, and none of them required re-intubation in the PACU stay.

\section{Discussion}

The aim of this pilot study was to understand the baseline incidence of RNMB and postoperative CREs, the feasibility of measuring TOF during the PACU stay in a tertiary hospital in Saudi Arabia. The incidence of RNMB in our cohort was $53.3 \%$, and postoperative CREs were observed among $66.7 \%$ of our cohort. The findings show that there was a statistically significant association between the incidence of RNMB and postoperative CREs. The finding of this study is consistent with the POPULAR study by Kirmeier et al. (2019), a recently published multicentre prospective observational study that examined 22803 patients who had undergone general anaesthesia. In this study, researchers have concluded that using the NMBDs was associated with an increased incidence of postoperative pulmonary complications $(7.6 \%, 1658 / 21694$; odd ratio $1.86,95 \%$ CI 1.53-2.26).

Based on the patients' demographic data and preoperative variables, which are presented in Table 4, the results of the current study do not show that female patients were significantly more likely to experience RNMB in the PACU than males $(p=0.033)$ as shown in Table 4. These findings are consistent with other studies conducted by Aytac et al. (2016), Pietraszewski and Gaszyński (2013) and Kaan et al. (2012). This could be that women are more sensitive to rocuronium, the onset time of rocuronium is shorter in women and its effective period is prolonged (Xue et al. 1997 and Adamus et al. 2008). They also added that the variability of sensitivity and action duration of NMBDs between women and 
Table 3 Demographic data

\begin{tabular}{|c|c|}
\hline Variables & Findings $(n=30)$ \\
\hline Age (years), median (IQR) & $35(27-53)$ \\
\hline \multicolumn{2}{|l|}{ Gender, n (\%) } \\
\hline Male & $17(56.7 \%)$ \\
\hline Female & 13(43.3\%) \\
\hline \multicolumn{2}{|l|}{ ASA-PS class, $n(\%)$} \\
\hline 1 & $10(33.3 \%)$ \\
\hline$\|$ & $17(56.7 \%)$ \\
\hline III & $3(10 \%)$ \\
\hline $\mathrm{BMI}\left(\mathrm{kg} / \mathrm{m}_{2}\right)$, mean $\pm \mathrm{SD}$ & $29.45 \pm 5.56$ \\
\hline \multicolumn{2}{|l|}{ Type of surgery, n (\%) } \\
\hline General & $13(43.3 \%)$ \\
\hline Urology & $4(13.3 \%)$ \\
\hline ENT & $10(33.3 \%)$ \\
\hline Plastic & $2(6.7 \%)$ \\
\hline $\mathrm{OB} / \mathrm{GYN}$ & $1(3.3 \%)$ \\
\hline \multicolumn{2}{|l|}{ NMBD used, $n(\%)$} \\
\hline Succinylcholine & $1(3.3 \%)$ \\
\hline Rocuronium & $26(86.7 \%)$ \\
\hline Cisatracurium & $3(10 \%)$ \\
\hline \multicolumn{2}{|l|}{ Reversal used, $n$ (\%) } \\
\hline None & $7(23.3 \%)$ \\
\hline Neostigmine & $23(76.7 \%)$ \\
\hline
\end{tabular}

$n$ (\%) number (percentage), IQR interquartile range, $\pm S D \pm$ standard deviation, ASA-PS class American Society of Anaesthesiologists Physical Status class, BMI body mass index, $\mathrm{kg} / \mathrm{m}^{2}$ kilogramme per metre square, ENT ear, nose and throat, $O B / G Y N$ obstetrics and gynaecology, NMBD neuromuscular blocking drug

men is believed to be associated with physiological differences in body structures. Whilst Aytac et al. (2016) also found that female patients undergoing anaesthesia of short duration are more likely to have RNMB in the PACU. Therefore, both Xue et al. (1997) and Adamus et al. (2008) suggest that the dose of rocuronium routinely used in females could be reduced.

Other significant findings in the current studies that the incidence of RNMB is significantly more frequent among patients for whom neuromuscular monitoring (acceleromyography) has not been used prior to extubation $(p=0.046)$. Several observational studies conducted in different countries (Fuchs-Buder et al. 2003; Grayling and Sweeney 2007; Sorgenfrei et al. 2005) have reported similar to this, but they cannot be directly compared because they used different techniques for neuromuscular monitoring. And this was also supported by Murphy et al. (2008b) who found that RNMB was more common in the conventional monitoring group than that in the quantitative monitoring group $(p<0.001)$.

The findings of this study suggest that there was a significant difference in the incidence of RNMB in relation to the duration of surgery whether short or long $(<90$ min compared with $\geq 90$ min; $p=0.001$ ). Stewart et al. (2016) also showed agreement with the findings as the RNMB was significantly more likely to be associated with shorter operations $(p=0.001)$. The agreement among the conclusions of these two studies could be referred to the fact that sufficient time is required for neostigmine to provide effective reversal, or as Miller (2011) for spontaneous recovery from neuromuscular blockade to a TOF ratio $\geq 0.90$, which may not be allowed during shorter surgery times.

Despite advances in the neuromuscular monitoring methods and pharmacological agents used in anaesthesia practice, the findings of this study showed that postoperative CREs were significantly associated with RNMB ( $p$ $=0.001)$, which was consistent with the previous studies (Grosse-Sundrup et al. 2012; Murphy et al. 2008a; Murphy et al. 2008b; Norton et al. 2013; Sauer et al. 2011) as shown in Table 5. Murphy et al. (2008b) in their study have examined the effectiveness of quantitative

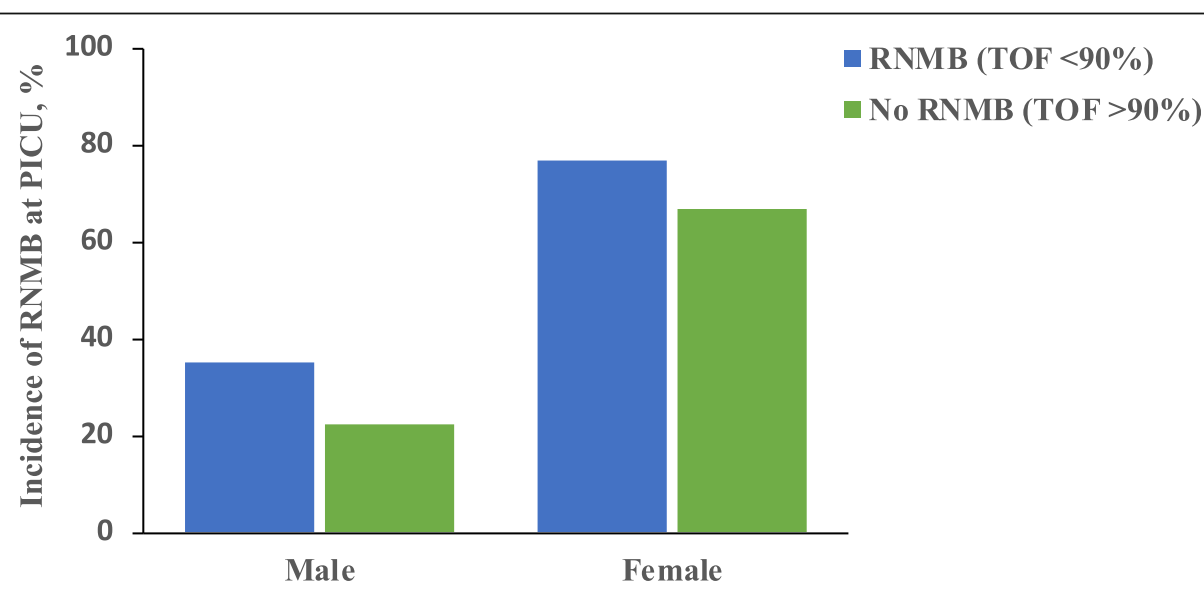

Fig. 2 The incidence of RNMB among the sample based on their gender 
Table 4 Patient characteristics and the incidence of RNMB

\begin{tabular}{|c|c|c|c|}
\hline Variables & RNMB (TOF ratio $<0.90$ ), $n=16$ & No RNMB (TOF ratio $\geq 0.90$ ), $n=14$ & $P$ value \\
\hline \multicolumn{4}{|l|}{ Age, $n(\%)$} \\
\hline $18-50$ vs. $\geq 51$ years & $11(50 \%)$ vs. 5 (62.5\%) & $11(50 \%)$ vs. $3(37.5 \%)$ & 0.0544 \\
\hline \multicolumn{4}{|l|}{ Gender, $n(\%)$} \\
\hline Male/female & $6(35.3 \%) / 10(76.9 \%)$ & $11(64.7 \%) / 3(23.1 \%)$ & 0.033 \\
\hline \multicolumn{4}{|l|}{ ASA-PS class, $n(\%)$} \\
\hline । & 7 (43.8\%) & $3(21.4 \%)$ & \\
\hline$\|$ & $9(56.3 \%)$ & $8(57.1 \%)$ & 0.103 \\
\hline III & $0(0.0 \%)$ & $3(21.4 \%)$ & \\
\hline BMI $\left(\mathrm{kg} / \mathrm{m}^{2}\right)$, mean $\pm \mathrm{SD}$ & $30.82 \pm 5.29$ & $28.53 \pm 6.41$ & 0.294 \\
\hline \multicolumn{4}{|l|}{ Neuromuscular monitoring before extubation, $n(\%)$} \\
\hline Yes/no & $2(22.2 \%) / 14(66.7 \%)$ & 7 (77.8\%)/7 (33.3\%) & 0.046 \\
\hline Duration of the surgery, $<90 \mathrm{~min}$ vs. $\geq 90 \mathrm{~min}$ & $13(81.8 \%)$ vs. $3(21.4 \%)$ & $3(18.8 \%)$ vs. $11(78.6 \%)$ & 0.001 \\
\hline $\mathrm{SpO}_{2}$, upon arrival in the PACU, median (IQR) & $91(90-93)$ & $96(91-100)$ & 0.034 \\
\hline RR (breaths/min), upon arrival in the PACU, median (IQR) & $22(19-25)$ & $20(16-21)$ & 0.025 \\
\hline
\end{tabular}

(acceleromyography) and qualitative neuromuscular monitoring in reducing the incidence of RNMB after tracheal extubation. They found that RNMB (TOF ratio < 0.90) was more frequent in the conventional group (30\%) compared with the acceleromyography group (4.5\%; $p<0.001)$. In addition, the authors revealed that mild hypoxaemia $\left(\mathrm{SpO}_{2} 90-93 \%\right)$ was significantly more frequent in the conventional group ( $43.3 \%$ vs. $6.7 \%)$, and severe hypoxaemia $\left(\mathrm{SpO}_{2}<90 \%\right)$ was also more common in the conventional group during the first $30 \mathrm{~min}$ of their PACU stay (21.1\%; all $p<0.001)$. The result of Murphy et al. (2008b) suggested that RNMB is significantly associated with hypoxaemia, which was similar to the findings of the current study.

Postoperative CREs occurred in twenty patients (66.7\%), and there were significantly more of these CREs among patients with RNMB ( $p=0.001)$. Xará et al. (2015) examined 340 patients and found that CREs happened in 67 of them (19.7\%), and CREs were more frequent in patients with RNMB $(p<.001)$. Moreover, among the 599 patients studied by Stewart et al. (2016), 97 participants experienced one or more CREs in the PACU, and these CREs were more frequent in patients with $\operatorname{RNMB}(p=0.033)$. In addition, Stewart et al. (2016) observed some CREs that were not observed by Xará et al. (2015) or by the current study, such as pulmonary aspiration after tracheal extubation or the need for assisted ventilation. However, the differences in findings among these studies could be impacted by either the sample size or the type of patients recruited during the studies.

There were no significant differences between the age of patients and the incidence of postoperative CREs ( $p=$ 0.62) in the current study. However, Cedborg et al. (2014) found that there was an intense negative effect on airway integrity in elderly patients with increased prevalence of pharyngeal dysfunction: from $37 \%$ in patients without RNMB to $71 \%$ during the presence of RNMB. Pedersen (1994) examined the risk factors associated with postoperative complications following general anaesthesia and found that postoperative

Table 5 Comparison between the variables with the presence or absence of CREs upon arrival in the PACU

\begin{tabular}{llll}
\hline Variables & CRE $(\boldsymbol{n}=\mathbf{2 0})$ & No CREs $(\boldsymbol{n}=\mathbf{1 0})$ & $\boldsymbol{P}$ value \\
\hline Age (years), median (IQR) & $35(27-51)$ & $35(30-53)$ & 0.62 \\
$\mathrm{BMI}\left(\mathrm{kg} / \mathrm{m}^{2}\right)$, mean $\pm \mathrm{SD}$ & $31.23 \pm 6.17$ & $26.78 \pm 3.94$ & 0.047 \\
Duration of surgery (min), median (IQR) & $82(75-161)$ & $106(86-158)$ & 0.403 \\
Temperature $\left({ }^{\circ} \mathrm{C}\right)$, median (IQR) & $36.50(36.40-36.80)$ & $36.65(36.40-36.90)$ & 0.689 \\
TOF ratio upon arrival in the PACU, median (IQR) & $0.88(0.72-0.89)$ & $0.96(0.91-1.00)$ & 0.001 \\
Incidence of RNMB (TOF ratio $<0.90), n(\%)$ & $15(75 \%)$ & $1(10 \%)$ & 0.001 \\
\hline
\end{tabular}

n (\%) number (percentage), IQR interquartile range, $\pm S D \pm$ standard deviation, $C R E s$ critical respiratory events, $B M I$ body mass index, $\mathrm{kg} / \mathrm{m}^{2} \mathrm{kilogramme}$ per metre square, min minutes, TOF train-of-four, PACU post-anaesthesia care unit, RNMB residual neuromuscular blockade 
Table 6 Incidence of CREs in the PACU

\begin{tabular}{ll}
\hline Variable & Incidence \\
\hline Upper airway obstruction & $5(16.7 \%)$ \\
Mild-moderate hypoxaemia & $9(30 \%)$ \\
Severe hypoxaemia & $4(13.3 \%)$ \\
Signs of respiratory distress & $15(50 \%)$ \\
Inability to breathe deeply & $2(6.7 \%)$ \\
Upper airway weakness & $3(10 \%)$ \\
\hline
\end{tabular}

pulmonary complications were associated with elderly patients. Therefore, the differences in the complications among the previous studies and the current study might be impacted by the age of their samples included (Sieber and Barnett 2011).

The results of this study seem to suggest a significant association between BMI and postoperative CREs during the early PACU stay. BMI $\left(31.23 \pm 6.1 \mathrm{~kg} / \mathrm{m}^{2}\right)$ was significantly greater $(p=0.047)$ among patients who experienced CREs compared to those who did not $\left(26.78 \pm 3.94 \mathrm{~kg} / \mathrm{m}^{2}\right)$. According to the World Health Organization (2016), subjects with BMI equal to or greater than $30 \mathrm{~kg} / \mathrm{m}^{2}$ are considered obese. Obesity has physiological effects on the respiratory system's compliance and lung volumes and that BMI was significantly associated with severe hypoxaemia $\left(\mathrm{SpO}_{2}<90 \%\right)$ during the PACU stay ( $p=0.01$ ) (Hodgson et al. 2015; Cammu et al. (2012).

The findings reported here can improve the current knowledge and clinical practice of perioperative management, specifically the management of NMBDs. The first step for improving NMBDs' management and postoperative outcomes is basically through following the evidence-based medical management of NMBDs, which can help to reduce complications initiated by unsuitable perioperative management. Therefore, based on the current literature and AAGBI guidelines (2016), the researcher recommends that neuromuscular monitoring in the operating theatre before extubation is required for all patients who have received NMBDs. Quantitative neuromuscular monitoring (acceleromyography) is essential to accurately assess the TOF ratio, which can help to diminish the incidence of RNMB. This will also help to prevent the postoperative complications associated with $\mathrm{RNMB}$ and that will reduce the incidence of postoperative critical respiratory events.

The current pilot study has some limitations that need to be mentioned. The convenience sampling method, time frame and sample size were applicable and appropriate for this study. The researcher was limited by resources and time boundaries; hence, the sample employed was small, which might reduce the external validity of the findings of the current study (LoBiondoWood and Haber 2014). However, the lack of generalizability and sampling bias are the main disadvantages of this sampling method (Polit 2014). The study was carried out only on elective surgical patients in a single tertiary hospital, and therefore, the results might be difficult to generalise to other surgical populations or to different settings (Greenhalgh 2014). Moreover, the present study was a prospective, observational study: no interventions were made in anaesthetic practice during the pre-operative, intra-operative or post-operative period, and all treatments were applied and managed according to the standards of the clinician who was in charge of each patient that day.

Further research into the association between the incidence of RNMB and postoperative CREs following general anaesthesia should address the limitations of this pilot study. With a CRE rate of $66 \%$, this pilot study certainly demonstrates the need for further multicentre, randomised trials in Saudi Arabia to provide better findings and more conclusive results. Enrolment of large samples is necessary for the appropriate detection of associations with the incidence of RNMB and postoperative CREs.

\section{Conclusion}

This is the first study conducted in Saudi Arabia that has investigated the baseline incidence of RNMB and postoperative CREs among patients undergoing elective surgery under general anaesthesia. This study observed evidence that the majority of patients with RNMB (TOF ratio < 0.90) experienced CREs in the PACU. In this study, the analysis demonstrated that high BMI (31.23 \pm $6.1 \mathrm{~kg} / \mathrm{m}^{2}$ ) can also contribute to CREs during the early PACU stay. Through further descriptive analysis of the sample characteristics, it was shown that female gender, shorter duration of surgery and the absence of intraoperative quantitative neuromuscular monitoring were the variables that were most likely to lead to the occurrence of RNMB (TOF ratio < 0.90).

In agreement with previous researches, the current study confirms the continued high incidence of RNMB upon PACU arrival during regular clinical practice, despite the use of neostigmine and qualitative TOF monitoring. Routine quantitative neuromuscular monitoring is recommended to enhance patient safety. Therefore, these results should provoke a re-evaluation of current practice and techniques used for the monitoring and reversal of NMBDs in anaesthesia practice in Saudi Arabia. The limitations of this research, as highlighted above, along with the suggested recommendations for future practice, will provide further evidence to supplement the current research and the extant literature, which is essential in improving the quality of anaesthesia practice. 


\section{Abbreviations}

PACU: Post-anaesthesia care units; NMBDs: Neuromuscular blocking drugs; NMBD: Neuromuscular blocking drug; RNMB: Residual neuromuscular blockade; TOF: Train-of-four; CREs: Critical respiratory events; BMI: Body mass index; ASA-PS: American Society of Anaesthesiologists Physical Status; $\mathrm{SpO}_{2}$ : Oxygen saturation; RR: Respiratory rate

\section{Acknowledgements}

We would like to thank the Anaesthesia Department, King Abdulaziz Medical City, for their cooperation during the data collection.

\section{Authors' contributions}

FKA, principal investigator: research idea, study design, data collection, data analysis, interpretation of the results and writing of the manuscript. KA: study design, ethical approvals and interpretation of the results. MMA: interpretation of the data. LO: interpretation of the data. MA, co-author: par ticipant recruitment and data collection. All authors read and approved the final manuscript.

\section{Funding}

College of Applied Medical Sciences King Saud bin Abdulaziz University for Health Sciences, King Abdullah International Medical Research Center (KAIM RC), King Abdullaziz Medical City, National Guard Health Affairs, Riyadh, Saudi Arabia.

\section{Availability of data and materials} Available

\section{Declarations}

\section{Ethics approval and consent to participate}

Obtained

\section{Consent for publication}

Obtained

\section{Competing interests}

The authors declare that they have no competing interests.

\section{Author details}

${ }^{1}$ Anesthesia Technology Program, College of Applied Medical Sciences, King Saud bin Abdul-Aziz University for Health Sciences, Riyadh, Saudi Arabia. ${ }^{2}$ King Abdullah International Medical Research Center, Riyadh, Saudi Arabia. ${ }^{3}$ School of Nursing and Midwifery, Faculty of Health, Education and Life Sciences, BCU, Birmingham, UK. ${ }^{4}$ Respiratory Therapy Program, College of Applied Medical Sciences, King Saud bin Abdul-Aziz University for Health Sciences, Riyadh, Saudi Arabia.

\section{Received: 24 April 2020 Accepted: 22 March 2021}

Published online: 04 May 2021

\section{References}

Adamus M, Gabrhelik T, Marek O. Influence of gender on the course of neuromuscular block following a single bolus dose of cisatracurium or rocuronium. Euro J Anaesthesiol. 2008;25(7):589-95. https://doi.org/10.1017/ S026502150800402X.

Aytac I, et al. Survey of postoperative residual curarization, acute respiratory events and approach of anesthesiologists. Brazilian J Anesthesiol (English edition). 2016;66(1):55-62.

Buhre W, Rossaint R. Perioperative management and monitoring in anaesthesia. Lancet. 2003;362(9398):1839-46. https://doi.org/10.1016/S0140-6736(03)14 905-7.

Butterworth JF. Morgan \& Mikhail's clinical anesthesiology. 5th ed. New York: New York: McGraw-Hill; 2013.

Cammu G, et al. A prospective, observational study comparing postoperative residual curarisation and early adverse respiratory events in patients reversed with neostigmine or sugammadex or after apparent spontaneous recovery. Anaesthesia and intensive care. 2012;40(6):999.

Cedborg HAl, et al. Pharyngeal function and breathing pattern during partial neuromuscular block in the elderly: effects on airway protection.
Anesthesiology. 2014;120(2):312-25. https://doi.org/10.1097/ALN. 0000000000000043

Claudius C, Garvey LH, Viby-Mogensen J. The undesirable effects of neuromuscular blocking drugs. Anaesthesia. 2009;64(s1):10-21. https://doi. org/10.1111/j.1365-2044.2008.05866.x.

Fortier L-P, McKeen D, Turner K, de Médicis É, Warriner B, Jones PM, et al. The RECITE study: a Canadian prospective, multicenter study of the incidence and severity of residual neuromuscular blockade. Anesthesia and Analgesia. 2015;121(2):366-72. https://doi.org/10.1213/ANE.0000000000000757.

Fuchs-Buder T, Hofmockel R, Geldner G, Diefenbach C, Ulm K, Blobner M. Einsatz des neuromuskulären Monitorings in Deutschland. Der Anaesthesist. 2003; 52(6):522-6. https://doi.org/10.1007/s00101-003-0508-9.

Grayling M, Sweeney B. Recovery from neuromuscular blockade: a survey of practice. Anaesthesia. 2007;62(8):806-9. https://doi.org/10.1111/j.1365-2044.2 007.05101.x.

Greenhalgh T. How to read a paper: the basics of evidence-based medicine. 5th ed. Chichester, West Sussex: Wiley; 2014.

Grosse-Sundrup $M$, et al. Intermediate acting non-depolarizing neuromuscular blocking agents and risk of postoperative respiratory complications: prospective propensity score matched cohort study. British Med J. 2012:345:1-14

Herbstreit F, Peters J, Eikermann M. Impaired upper airway integrity by residual neuromuscular blockade increased airway collapsibility and blunted genioglossus muscle activity in response to negative pharyngeal pressure. Anesthesiology. 2009;110(6):1253-60. https://doi.org/10.1097/A LN.0b013e31819faa71.

Hodgson LE, Murphy PB, Hart N. Respiratory management of the obese patient undergoing surgery. J Thorac Dis. 2015;7(5):943-52. https://doi.org/10.3978/j. issn.2072-1439.2015.03.08.

Kaan N, Kocaturk O, Kurt I, Cicek $\mathrm{H}$. The incidence of residual neuromuscular blockade associated with single dose of intermediate-acting neuromuscular blocking drugs. Middle East J Anesthesiol. 2012;21(4):535-42.

Kiekkas P, Bakalis N, Stefanopoulos N, Konstantinou E, Aretha D. Residual neuromuscular blockade and postoperative critical respiratory events: literature review. J Clin Nurs. 2014;23(21-22):3025-35. https://doi.org/10.1111/jocn.12508.

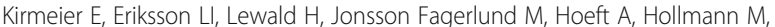
et al. Post-anaesthesia pulmonary complications after use of muscle relaxants (POPULAR): a multicentre, prospective observational study. Lancet Respir Med. 2019;7(2):129-40. https://doi.org/10.1016/S2213-2600(18)30294-7.

LoBiondo-Wood G, Haber J. Nursing research: methods and critical appraisal for evidence based practice. 8th ed. St. Louis, MO: Elsevier Mosby; 2014.

Miller RD. Basics of anesthesia. 6th ed Philadelphia: 6th ed; 2011.

Murphy GS. Residual neuromuscular blockade: incidence, assessment, and relevance in the postoperative period. Minerva Anestesiol. 2006;72(3):97-109.

Murphy GS, Szokol JW, Avram MJ, Greenberg SB, Marymont JH, Vender JS, et al. Intraoperative acceleromyography monitoring reduces symptoms of muscle weakness and improves quality of recovery in the early postoperative period. Anesthesiology. 2011;115(5):946-54. https://doi.org/10.1097/ALN.0b013e31 82342840 .

Murphy GS, Szokol JW, Avram MJ, Greenberg SB, Shear TD, Vender JS, et al. Residual neuromuscular block in the elderly: incidence and clinical implications. Anesthesiology. 2015;123(6):1322-6. https://doi.org/10.1097/ALN 0000000000000865

Murphy GS, Szokol JW, Marymont JH, Greenberg SB, Avram MJ, Vender JS. Residual neuromuscular blockade and critical respiratory events in the postanesthesia care unit. Anesthesia and Analgesia. 2008a;107(1):130-7. https://doi.org/10.1213/ane.0b013e31816d1268.

Murphy GS, et al. Intraoperative acceleromyographic monitoring reduces the risk of residual meeting abstracts and adverse respiratory events in the postanesthesia care unit. J Am Soc Anesthesiol. 2008b;109(3):389-98.

Norton M, Xará D, Parente D, Barbosa M, Abelha FJ. Residual neuromuscular block as a risk factor for critical respiratory events in the post anesthesia care unit. Revista Española de Anestesiología y Reanimación. 2013;60(4):190-6. https://doi.org/10.1016/j.redar.2012.12.011.

Pedersen T. Complications and death following anaesthesia. A prospective study with special reference to the influence of patient-, anaesthesia-, and surgeryrelated risk factors. Danish Med Bull. 1994;41(3):319-31.

Pietraszewski P, Gaszyński T. Residual neuromuscular block in elderly patients after surgical procedures under general anaesthesia with rocuronium. Anaesthesiol Intensive Therap. 2013;45(2):77-81. https://doi.org/10.5603/AIT.2 013.0017. 
Polit DF. Essentials of nursing research: appraising evidence for nursing practice. 8th ed. Philadelphia; London: Wolters Kluwer Health/Lippincott Williams \& Wilkins; 2014

Sauer M, Stahn A, Soltesz S, Noeldge-Schomburg G, Mencke T. The influence of residual neuromuscular block on the incidence of critical respiratory events. A randomised, prospective, placebo-controlled trial. European J Anaesthesiol (EJA). 2011;28(12):842-8. https://doi.org/10.1097/EJA.0b013e328345cd11.

Sieber FE, Barnett SR. Preventing postoperative complications in the elderly. Anesthesiol clin. 2011;29(1):83-97. https://doi.org/10.1016/j.anclin.2010.11.011.

Sorgenfrei I, Viby-Mogensen J, Swiatek FA. Does evidence lead to a change in clinical practice? Danish anaesthetists' and nurse anesthetists' clinical practice and knowledge of postoperative residual curarization. Ugeskrift for laeger. 2005;167(41):3878-82.

Stewart PA, Liang SS, Li QS, Huang ML, Bilgin AB, Kim D, et al. The impact of residual neuromuscular blockade, oversedation, and hypothermia on adverse respiratory events in a postanesthetic care unit: a prospective study of prevalence, predictors, and outcomes. Anesthesia \& Analgesia. 2016;123(4): 859-68. https://doi.org/10.1213/ANE.0000000000001513.

World Health Organization. 2016. WHO | Obesity and overweight [Online]. [Online]. Available at: http://www.who.int/mediacentre/factsheets/fs311/en/ [Accessed: 05 May 2017].

Xará $\mathrm{D}$, et al. Adverse respiratory events in a post-anesthesia care unit. Archivos de Bronconeumología (English Edition). 2015;51(2):69-75.

Xue FS, Tong SY, Liao X, Liu JH, An G, Luo LK. Dose-response and time course of effect of rocuronium in male and female anesthetized patients. Anesthesia and Analgesia. 1997:85(3):667-71, Dose-Response and Time Course of Effect of Rocuronium in Male and Female Anesthetized Patients. https://doi.org/1 0.1213/00000539-199709000-00033.

\section{Publisher's Note}

Springer Nature remains neutral with regard to jurisdictional claims in published maps and institutional affiliations.

Ready to submit your research? Choose BMC and benefit from:

- fast, convenient online submission

- thorough peer review by experienced researchers in your field

- rapid publication on acceptance

- support for research data, including large and complex data types

- gold Open Access which fosters wider collaboration and increased citations

- maximum visibility for your research: over $100 \mathrm{M}$ website views per year

At $\mathrm{BMC}$, research is always in progress.

Learn more biomedcentral.com/submissions 